\title{
Prevalence of Alzheimer plaques in AIDS
}

\author{
Margaret M Esiri, Simon C Biddolph, Christine S Morris
}

\begin{abstract}
Objectives-Both genetic and environmental risk factors for Alzheimer's disease have been identified. The best established environmental risk factor, head trauma, is thought to act through the triggering of an inflammatory response. Another stimulus to an inflammatory response in the brain is AIDS. Whether there is an increased prevalence of $\beta / A 4$ amyloid deposits in the form of argyrophilic plaques in the brains of patients with AIDS has therefore been investigated.

Methods-The prevalence of argyrophilic amyloid plaques in the cerebral cortex of frontal and temporal lobes was compared in 97 cases of AIDS dying at ages 30-69 years with that in 125 age matched, non-HIV infected controls.

Results-In the control group, and in AIDS, the prevalence of plaques increased with age $(p=0.005$ and 0.048 respectively). There was a significantly greater prevalence of argyrophilic plaques in the AIDS group as a whole $(29 \%)(p<0.004)$ and in those in the fourth decade $(18 \%)(p<0.014)$ than in control subjects $(13 \%$ and $0 \%$ respectively).

Conclusion-There is a predisposition to argyrophilic plaque formation in the brain in AIDS. The findings support the view that a stimulus to an inflammatory response in the brain favours argyrophilic plaque formation. The clinical relevance of our findings is, as yet, unclear.

(F Neurol Neurosurg Psychiatry 1998;65:29-33)
\end{abstract}

Keywords: AIDS; Alzheimer's disease; amyloid plaques

Alzheimer's disease is characterised pathologically chiefly by the presence of widely distributed cerebral argyrophilic plaques and neurofibrillary tangles. ${ }^{1}$ A principal component of argyrophilic plaques is $\beta / \mathrm{A} 4$ amyloid, a peptide derived from the metabolic processing of a larger, glycosylated membrane protein, amyloid precursor protein. ${ }^{23}$ Argyrophilic plaques have different morphological forms, classified as diffuse, classic, and "burnt out". ${ }^{4}$ Diffuse plaques consist of focal but dispersed deposits of $\beta / \mathrm{A} 4$ amyloid, well demonstrated immunocytochemically with antibodies to $\beta / A 4$ protein and with the methenamine silver stain..$^{5-8}$ Classic plaques have a central, dense core of $\beta / \mathrm{A} 4$ amyloid and a surrounding corona of abnormal neuritic and glial cell processes. Burnt out plaques consist of a dense deposit of $\beta / \mathrm{A} 4$ amyloid resembling the core of classic plaques without the surrounding neuritic and other cell processes.
According to the amyloid hypothesis for the pathogenesis of Alzheimer's disease, diffuse plaques are the initial manifestation of the disease, with neuritic or classic plaques and burnt out plaques developing later. ${ }^{910}$ Concurrent with plaque accumulation and progression, neurofibrillary tangles, initially appearing only in the transentorhinal region, become more numerous and widespread in the hippocampus and eventually in the neocortex and certain subcortical nuclei. ${ }^{11}$ Typically, the progression of disease from the initial, diffuse, plaque stage to the advanced state with widespread neocortical neuritic plaques and neurofibrillary tangles is estimated to take at least 20 years. This is based on findings on the prevalence of these changes in brains from patients of differing ages with adult Down's syndrome, who almost invariably develop the pathology of Alzheimer's disease by late middle age, ${ }^{12}$ and in elderly populations. ${ }^{1314}$ The early stages of this pathological sequence, before the widespread development of neuritic pathology, are largely subclinical.

Although there is indubitable evidence for an important genetic influence in the development of these changes, both in familial and sporadic Alzheimer's disease, ${ }^{15-20}$ it is also thought likely that environmental factors play a significant part in their development. Three separate epidemiological studies, among nine that considered the possibility, have pointed to the importance of previous head injury in increasing the risk of developing clinical Alzheimer's disease. ${ }^{21}$ One reason for this might be that head injury produces irreversible damage to the brain which reduces its reserve capacity and makes symptoms develop at an earlier stage in the evolution of the pathology of Alzheimer's disease. ${ }^{22}$ However, it is also possible that head injury accelerates, or makes more likely, the development of Alzheimer's disease pathology itself. Thus, in dementia pugilistica, pathological features resembling those seen in Alzheimer's disease develop in boxers subjected to repeated head injury. ${ }^{23}$ Recent pathological studies exploring a possible link between head injury and Alzheimer's disease have found an increased prevalence of $\beta / \mathrm{A} 4$ amyloid deposits in subjects dying four hours to 2.5 years after severe head injury compared with age matched controls with no history of previous head injury. ${ }^{24}{ }^{25}$ Possession of the apolipoprotein $\mathrm{E}$ gene allele $\varepsilon 4$ increases both the risk of developing Alzheimer's disease, ${ }^{19}{ }^{20}$ particularly after head injury, ${ }^{26}$ and the risk of having $\beta / \mathrm{A} 4$ amyloid deposits in the brain after head injury. ${ }^{27}$ It is hypothesise ${ }^{28}$ that head injury provokes enhanced production of amyloid precursor protein as part of an acute phase response, possibly mediated by interleukin-1, and in revised form 14

November 1997

Accepted 25 November 1997 
Table 1 Plaque distribution and density in HIV infected cases and controls

\begin{tabular}{lll}
\hline & $H I V+$ & $H I V-$ \\
\hline Temporal lobe and frontal lobe plaques & 17 & 12 \\
Only temporal lobe plaques & $11^{\star}$ & 2 \\
Plaque profile densities (mean (SD)) $\dagger$ & $2.14 \quad(3.17)$ & $3.40 \quad(3.89)$ \\
\hline
\end{tabular}

*In six cases a frontal lobe section was not available for examination.

$\dagger$ Difference NS by Mann-Whitney non-parametric test $(p=0.78)$.

which has been shown to upregulate production of amyloid precursor protein in cultured cells. $^{29-32}$ This enhanced production of amyloid precursor protein, it is suggested, in turn results in increased $\beta / \mathrm{A} 4$ amyloid deposits in the brain.

If this hypothesis is correct it might be anticipated that other disease processes predisposing to increased interleukin-1 production in the brain may likewise result in an enhanced risk of developing $\beta / \mathrm{A} 4$ amyloid deposits. The chronic viral infection that causes AIDS, HIV-1, is estimated to infect the brain in $20 \%$ $80 \%$ of AIDS cases, depending on the populations studied and the sensitivity of the method used to detect such infection. ${ }^{33}$ Furthermore, interleukin-1 is one of several cytokines that has been shown to be produced in increased amounts in the brain in AIDS. ${ }^{34}$ These findings suggest the possibility that patients with AIDS, like those with head injury, may be at increased risk of developing amyloid plaques in the cerebral cortex. We have therefore examined sections of cerebral cortex from patients with AIDS dying from 30 to 69 years of age and compared the prevalence of argyrophilic amyloid deposits in those patients with that in age matched controls without HIV infection.

\section{Materials and methods}

Material from 97 patients with HIV-1 infection (10 pre-AIDS, 87 AIDS) (91 men, five women), aged over 29 years at death (mean (SD) 47.6 (10.2), range 30-67 years) was obtained from the MRC AIDS brain bank at the Institute of Psychiatry, London and at its satellites in Oxford and Edinburgh, or from the Institute of Neurology, London. Age matched controls (mean (SD) 49.8 (10.1), range 30-68 years) without cerebral disease (77 men, 48 women), were obtained from 125 necropsies, most of which were performed before the onset of the AIDS epidemic, from Runwell Hospital, Essex (Corsellis collection) $(n=110)$ and from the Radcliffe Infirmary, Oxford $(n=15)$. These were selected on the basis that they had shown no evidence in life of disease of the CNS and had no CNS macroscopic pathology on neuropathological examination. Large sections

Table 2 Risk category for HIV in relation to prevalence of argyrophilic plaques

\begin{tabular}{llllll}
\hline & & \multicolumn{4}{l}{ Argyrophilic plaques } \\
\cline { 5 - 6 } Risk factor for HIV & Age $(y)$ mean & $(S D)$ & Present & Absent & Total \\
\hline Homosexual & $50 \dagger$ & $(9.7)$ & $14^{\star}$ & 22 & 36 \\
Haemophiliac & 47 & $(9.7)$ & 5 & 13 & 18 \\
Drug misuser & $35 \dagger$ & $(3.8)$ & $2^{\star}$ & 17 & 19 \\
Uncertain & & & 7 & 17 & 24 \\
Total & & & 28 & 69 & 97 \\
\hline
\end{tabular}

^Difference between these two rows significant at $\mathrm{p}=0.03$.

+Difference between these two rows significant at $p=0.0001$ (Mann-Whitney non-parametric test). of temporal lobe/hippocampus and frontal lobes, or of hippocampus, entorhinal cortex, and temporal lobe were stained with the methenamine silver stain for argyrophilic plaques (which stains all $\beta /$ A 4 amyloid plaques) ${ }^{7}$ and systematically scanned for the presence of argyrophilic plaques, without knowledge of the age of each case. All sections were mounted on APTES (3-aminopropyl-triethoxysilane)coated slides and adjacent sections to those used for methenamine silver staining from HIV infected patients and a random selection of controls were processed for HIV p24 antigen. Randomly selected $\mathrm{HIV}^{+}$, methenamine silver ${ }^{+}$, and control $\mathrm{HIV}^{-}$, methenamine silver ${ }^{+}$cases were also immunostained for $\beta \mathrm{A} 4$. All sections were rehydrated, treated with $3 \%$ aqueous hydrogen peroxide $\left(\mathrm{H}_{2} \mathrm{O}_{2}\right)$ to block endogenous peroxidase. Then antigen retrieval for HIV p24 was performed by microwaving for $3 \times 5$ minutes on "high" in an $800 \mathrm{~W}$ microwave oven, and by pretreating with $98 \%$ formic acid for five minutes for $\beta \mathrm{A} 4$. After washes in phosphate buffered saline containing $0.01 \%$ Triton $\mathrm{X}-100$ (PBST), non-specific binding was blocked by incubation with foetal calf serum at 1:20 for 20 minutes, followed immediately by incubation in the primary antibodies, mouse monoclonal anti-HIV p24 (Dako) diluted 1:20 and rabbit anti- $\beta$ A4 (Insight Biotechnology), diluted 1:100, for one hour. After further washes as before, biotinylated goat antimouse immunoglobulins (at 1:200) and biotinylated goat antirabbit immunoglobulins at $1: 400$ (both from Dako) were applied as the secondary reagents for HIV p24 and $\beta$ A 4 respectively, for 30 minutes. After further washes in PBST, the tertiary reagent, streptavidin horseradish peroxidase (Dako), diluted at 1:300, was applied for 30 minutes. The reactions were visualised with 3-amino-9-ethylcarbazone (AEC) and lightly counterstained with Mayer's haemalum (Merck, BDH) and mounted in glycerol gelatin (Sigma). In sections that contained plaques, the mean density of plaque profiles per field averaged from an examination of 20 fields at $\times 200$ magnification was calculated, in each lobe.

The prevalence of patients with any argyrophilic plaques in male and female controls and in AIDS was compared with Fisher's exact test. Analysis of variance (ANOVA) was used to examine the relation between prevalence off plaques and age in both groups of cases. Analysis was made with Instat 2 for PCs (Graphpad).

\section{Results}

As men predominated in the AIDS series of patients whereas men and women were more evenly represented in the age matched control series,we first compared $\beta / A 4$ plaque prevalence between men and women in the control series. We found no significant effect of sex in this comparison (men, mean 2.9; women, mean 4.1) and therefore considered the control group as a whole appropriate to compare with the patients with AIDS for plaque prevalence.

Figure 1 shows the prevalence of cases showing any argyrophilic amyloid deposits in 
Table 3 Argyrophilic plaque prevalence relative to neuropathology in HIV infection

\begin{tabular}{lrrrr}
\hline Neuropathology & \multicolumn{2}{c}{ Plaque+ (\%) } & Plaque- & Total \\
\hline HIV encephalitis & 7 & $(33)$ & 14 & 21 \\
Opportunistic infections & 5 & $(29)$ & 12 & 17 \\
Lymphoma & 4 & $(20)$ & 12 & 16 \\
Other pathology, not known & 3 & $(33)$ & 6 & 9 \\
Non-specific or no pathology & 16 & $(32)$ & 33 & 49 \\
Total & & & & 112 \\
\hline
\end{tabular}

each decade in the AIDS cases and controls. The $\beta / \mathrm{A} 4$ immunostaining confirmed that all the silver positive deposits contained this antigen in cases infected with HIV and control cases examined. Age was significantly correlated with prevalence of plaques for controls $(p=0.005)$ and for AIDS cases $(p=0.048)$. The prevalence of cases with plaques rose from $18 \%$ in the fourth decade to $50 \%$ in the seventh decade in AIDS cases. In controls the equivalent figures were none in the fourth decade and $36 \%$ in the seventh decade. In the series as a whole $29 \%$ of AIDS cases and $14 \%$ of controls had plaques. The differences between AIDS and controls in the fourth decade and in the series as a whole were significant (p 0.014 and 0.004 respectively). In most of the cases plaques were sparse and of the diffuse variety in both AIDS and control groups. The distribution of plaques between the temporal and frontal cortex did not differ between AIDS and control groups and the overall mean density of plaque profiles did not differ either (table 1). Neuritic elements in plaques, or well defined cores, were found rarely in six AIDS cases and in three of the controls. In some AIDS cases and controls plaques showed a distribution closely related to neuron perikarya, as has been described in Down's syndrome. ${ }^{7}$ In no case among either the AIDS or control group were there sufficient neuritic plaques to diagnose Alzheimer's disease with CERAD neuropathological criteria. ${ }^{1}$ The duration of known HIV positive status in the AIDS cases, where known, was not related to presence of argyrophilic plaques (data not shown). Table 2 shows the influence of the risk category for AIDS on prevalence of plaques. Plaques were significantly more prevalent in homosexuals than drug misusers and haemophiliacs had an intermediate plaque prevalence. However, this difference between homosexuals and drug misusers is attributable to the different age at death of those in the different risk groups, the

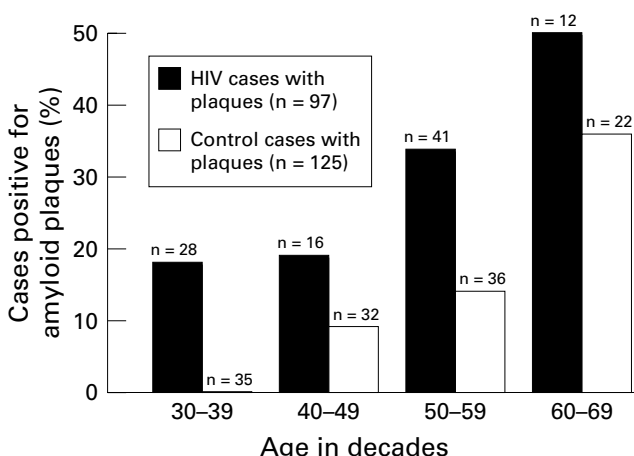

Age distribution of amyloid plaques in HIV cases $v$ controls. Numbers over the columns indicate the number of cases in each category. average age of the drug misusers being 35 years and of homosexuals and haemophiliacs 50 years and 47 years respectively. Insufficient information was available about cognitive function in life for us to be able to search for a correlation between presence of dementia in life and plaque pathology. Twenty five HIV infected patients had HIV encephalitis with HIV p24 core protein detected in the brain, seven of which had cortical argyrophilic plaques (aged 32, 39, 48, 52, 53, 56, and 59 years). This was not significantly different from the prevalence of plaques in patients with AIDS without detectable HIV p24 core protein. No HIV p24 core protein was detected in sections from control patients. The presence of additional neuropathology in the form of opportunistic infections, CNS lymphoma, or non-specific pathology (glial nodules, mild perivascular inflammatory cell infiltration, haemorrhages, and infarctions) did not significantly influence the prevalence of argyrophilic plaques (table 3$)$. In the few cases $(n=36)$ for which information was available about whether anti-HIV treatment was given or not, treatment did not influence risk of formation of plaques (data not shown). Of the few patients $(n=10)$ who had not developed clinical AIDS two (aged 39 and 44 years) showed some diffuse argyrophilic plaques. Brain weights between HIV infected men (mean (SD) 1444 (148) g) and controls (mean (SD) 1475 (127) g) did not differ significantly. Brain weights in the HIV infected subgroup with argyrophilic plaques (mean (SD) 1458 (142) g) and without argyrophilic plaques (mean (SD) 1420 (159) g) were likewise not significantly different.

\section{Discussion}

The prevalence of argyrophilic $\beta / \mathrm{A} 4-$ containing plaques in the control series in this study in the younger age groups was comparable with that found in previous large necropsy series, ${ }^{55-37}$ and rose significantly with age, as expected.

We found a significantly higher prevalence of cortical argyrophilic plaques in patients with AIDS dying in the fourth decade and in the series as a whole than in age matched control subjects. This is the first study, as far as we are aware, that has shown a relation between AIDS and argyrophilic plaque deposition. Many patients with AIDS die at an age when the prevalence of $\beta / A 4$ deposits is normally negligible. However, the present finding of argyrophilic plaques in $18 \%$ of those aged $30-39$ years with AIDS means that plaque prevalence in AIDS is increased to levels approaching those found in Down's syndrome. ${ }^{12}$ Plaque prevalence in the age group studied here was also increased in another study of epilepsy. ${ }^{36}$ The present study does not clarify when in the stage of HIV-1 infection enhanced argyrophilic plaque formation occurs, but it is noteworthy that of 10 patients in the present series who had not developed clinical AIDS, two (aged 39 and 44 years) had plaques. Thus there seems to be the potential for plaques to develop in the brain before the onset of clinical AIDS. 
The overwhelming majority of the plaques detected both in patients with AIDS and controls were diffuse and lacked any neuritic elements. The relation between diffuse and neuritic plaques is controversial. In support of the amyloid cascade hypothesis of Alzheimer's disease are findings that only diffuse plaques are seen initially in young adult subjects with Down's syndrome who invariably develop the full pathological picture of Alzheimer's disease including many neuritic plaques, if they live long enough. ${ }^{12}{ }^{38}$ Elderly undemented subjects also may have many diffuse plaques with few or no neuritic plaques in their brains, ${ }^{5}$ and subjects with Alzheimer's disease may have only diffuse plaques in certain regions of the brain such as the striatum and cerebellum. ${ }^{39}$ Thus diffuse plaques without neuritic plaques are commonplace whereas neuritic plaques in the absence of diffuse plaques do not occur. This finding is consistent with diffuse plaques developing into neuritic ones but other interpretations are also possible. Wisniewski et al has argued for a different source of the amyloid that forms neuritic plaques from that which forms diffuse ones. ${ }^{40}$

The clinical significance of our finding is uncertain. The extent of the Alzheimer's disease pathology that we found would not have been expected to give rise to symptoms of dementia on their own. However, some normally subclinical amounts of Alzheimer's disease pathology may contribute to clinical dementia if they are combined with other cerebral pathology such as vascular disease ${ }^{37}$ or Lewy body disease. ${ }^{41}$ So far the clinical studies of dementia in AIDS have suggested that, unlike Alzheimer's disease, the symptoms are indicative of a subcortical dementia. ${ }^{42} 43$

Our findings may have significance for an understanding of the pathogenesis of Alzheimer's disease. They support the view that brain infection or cytokine production may influence the course of the early stages of the putative pathogenetic process postulated by the amyloid hypothesis of Alzheimer's disease. Increased cytokine production in the brain in AIDS has been well described, ${ }^{34}$ including increased production of $1 \mathrm{~L}-1$ which is known to upregulate production of $\beta / A 4$ amyloid protein in vitro. ${ }^{29-32}$ Furthermore, increased expression of amyloid precursor protein in neurons in AIDS has been documented. ${ }^{44}$ In a transgenic mouse model of HIV neurodegeneration induced by gp120, expression of human APP751 in neurons significantly reduced the extent of neuron loss, synaptic degeneration, and gliosis suggesting that amyloid precursor protein expression has a protective effect in the presence of damage to the nervous system related to HIV. ${ }^{45}$ Other virus infections have occasionally been noted anecdotally to be associated with formation of argyrophilic plaques, but no systematic study of such associations has been undertaken. Latent herpes simplex virus infection of the brain has been circumstantially linked to Alzheimer's disease ${ }^{46}$ and a recent study implicated an interaction with apolipoprotein $\mathrm{E}$ (ApoE) genotype in such a linkage. ${ }^{47}$ It remains for further studies to investigate what addi- tional factors, other than age- - such as ApoE genotype-among those infected with HIV, may predispose to the apparently precocious deposition of $\beta / \mathrm{A} 4$ amyloid deposits in some cases of AIDS.

We thank the MRC AIDS brain banks in London (Professor P Lantos), and Edinburgh (Dr J Bell), Professor F Scaravilli (nstitute of Neurology, London), and the Corsellis Collection Runwell, Essex) for material used in this study. We also thank Mrs J Henderson and Ms J Keeble for typing the manuscript. This work was supported by grants from the UK Medical Research Council and the Wellcome Trust.

1 Mirra SS, Heyman A, McKeel D, et al. The consortium to establish a registry for Alzheimer's disease (CERAD), Part II: standardisation of the neuropathologic assessment of Alzheimer's disease. Neurology 1991;41:479-86.

2 Glenner GG, Wong CW. Alzheimer's disease: initial report of the purification and characterisation of a novel cerebrovascular amyloid protein. Biochem Biophys Res Commun 1984;120:885-90.

3 Kang J, Lemaine H-G, Unterbeck A, et al. The precursor of Alzheimer's disease amyloid A4 protein resembles a cell-surface receptor. Nature 1987;325:733-6.

4 Tomlinson BE. Ageing and the dementias. In: Adams JH, Duchen LW, eds. Greenfield's neuropathology 5th ed. London: Arnold, 1992:1284-410.

5 Davies L, Wolska B, Hilbich C, et al. A4 amyloid protein deposition and the diagnosis of Alzheimer's disease. deposition and the diagnosis

6 Ogomori K, Kitamoto T, Tateishi J, et al. $\beta$ Protein amyloid is widely distributed in the central nervous system of patients with Alzheimer's. Am F Pathol 1989;134:243-51.

7 Allsop D, Haga SI, Haga C, et al. Early senile plaques in Down's syndrome brains show a close relationship with cell bodies of neurons. Neuropathol Appl Neurobiol 1989;15: $531-42$

8 Lamy C, Duyckaerts C, Delaere P, et al. Comparison of seven staining methods for senile plaques and neurofibrillary tangles in a prospective series of 15 elderly patients. Neuropathol Appl Neurobiol 1989;15:563-78.

9 Hardy J, Allsop D. Amyloid deposition as the central event in the aetiology of Alzheimer's disease. Trends Pharmacol Sci 1991;12:383-8.

10 Selkoe DJ, Alzheimer's disease: a central role for amyloid. $\mathcal{F}$ Neuropathol Exp Neurol 1994;53:438-47.

11 Braak H, Braak E. Pathological staging of Alzheimer-related changes. Acta Neuropathol 1991;82:239-59.

12 Mann DMA, Esiri MM. The pattern of acquisition of plaques and tangles in the brain of patients under 50 years of age with Down's syndrome. F Neurol Sci 1989;89:16979.

$13 \mathrm{Ohm}$ TG, Müller $\mathrm{H}$, Braak $\mathrm{H}$, et al. Close meshed prevalence rates of different stages as a tool to uncover the rate of Alzheimer's disease-related neurofibrillary changes. Neuroscience 1995;64:209-17.

14 Tomlinson BE. The ageing brain. In: Smith WT, Cavanagh $\mathrm{B}$, eds. Recent advances in neuropathology. Edinburgh: Churchill Livingstone, 1981:129-59.

15 Goate A, Chartier-Harlin, Mullan M. Segregation of a missense mutation in the amyloid precursor protein gene with familial Alzheimer's disease. Nature 1991;349:704-6.

16 Sherrington R, Rogaev EI, Liang Y, et al. Cloning of a gene bearing missense mutations in early-onset familial Alzheimer's disease. Nature 1995;375:754-60.

17 Rogaev EI, Sherrington R, Rogaeva EA, et al. Familial Alzheimer's disease in kindreds with missense mutation in a gene on chromosome 1 related to the Alzheimer's disease type 3 gene. Nature 1995;376:775-8.

18 Levy-Lahed E, Wasco W, Poorkaj P, et al. Candidate gene for the chromosome 1 familial Alzheimer's disease locus. Science 1995;269:973-7.

19 Saunders AM, Strittmatter WJ, Schmechel D, et al. Association of apolipoprotein $\mathrm{E}$ allele epsilon 4 with late-onset familial and sporadic Alzheimer's disease. Neurology 1993; 43:1467-72.

20 Roses AD. Apolipoprotein E affects the rate of Alzheimer's disease expression. $\beta$ Amyloid burden is a secondary consequence dependent on APOE genotype and duration consequence dependent on APOE genotype and duration
of disease. I Neuropathol Exp Neurol 1994;53:429-37.

21 Mortimer JA, van Duijn CM, Chandra V, et al. Head injury as a risk factor for Alzheimer's disease: a collaborative re-analysis of case-control studies. Int f Epidemiol 1991;20 (suppl 2): 528-35.

22 Mortimer JA, Pirozzolo FJ. Remote effects of head trauma. Dev Neuropsychol 1985;1:215-29.

3 Roberts GW, Allsop D, Bruton CJ. The occult aftermath of boxing. I Neurol Neurosurg Psychiatry 1990;53:373-8.

24 Roberts GW, Gentleman SM, Lynch A, et al. $\beta / A 4$ amyloid protein deposition in brain after head trauma. Lancet 1991; ii: $1422-3$.

25 Roberts GW, Gentleman SM, Lynch, et al. $\beta$ amyloid protein deposition in the brain after severe head injury: protein deposition in the brain after severe head injury: Neurol Neurosurg Psychiatry 1994;57:419-25.

26 Mayeux R, Ottman R, Maestre G, et al. Synergistic effects of traumatic head injury and apolipoprotein-E4 in patients with Alzheimer's disease. Neurology 1995;45:555-7. 
27 Nicoll JAR, Roberts GW, Graham DI. Apolipoprotein E\&4 allele is associated with deposition of amyloid $\beta$ protein folallele is associated with deposition of amyloid

28 Gentleman SM, Graham DI, Roberts GW. Molecular pathology of head trauma; altered $\beta A P P$ metabolism and the aetiology of Alzheimer's disease. In: Kogure K, Hossmann K-A, Siesjo BK, eds. Prog Brain Res 1993;96: 237-46.

29 Goldgaber D, Harris HW, Hla T, et al. Interleukin -I regulates synthesis of amyloid ( $\beta$ protein precursor mRNA in human endothelial cells. Proc Natl Acad Sci USA 1989;86:7606-10.

30 Forloni G, Demicheli F, Giorgi S, et al. Expression of amyloid precursor protein $\mathrm{mRNAs}$ in endothelial, neuronal, and glial cells: modulation by interleukin-1. Brain Res Mol Brain Res 1992;16:128-34.

31 Buxbaum JD, Oishi M, Chen HI, et al. Cholinergic agonists and interleukin-1 regulate processing and secretion of the Alzheimer $\beta / A 4$ amyloid protein precursor. Proc Natl Acad Sci USA 1992;89:10075-8.

Sci USA 1992;89:10075-8.
32 Das S, Potter H. Expression of the Alzheimer amyloid$\mathrm{E}$ is induced in astrocytes by IL- 1 . Neuron $1995 ; 14: 447-56$. E is induced in astrocytes by IL-1. Neuron 1995; 14:447-56.
Masliah E, Adrian CL, Ge N, et al. Spectrum of human 3 Masliah E, Adrian CL, Ge N, et al. Spectrum of human

34 Tyor WR, Glass JD, Griffin JW, et al. Cytokine expression in the brain during the acquired immunodeficiency syndrome. Ann Neurol 1992;31:349-60.

35 Miller FD, Hicks SP, D'Amato CJ, et al. A descriptive study of neuritic plaques and neurofibrillary tangles in an autopsy population. Am $\mathcal{F}$ Epidemiol 1984;120:331-41.

36 Mackenzie IRA, Miller LA. Senile plaques in temporal lobe epilepsy. Acta Neuropathol 1994;87:504-10.

37 Del Ser T, Bermejo F, Portera A, et al. Vascular dementia; a clinico pathological study. F Neurol Sci 1990;96:1-17.
38 Wisniewski HM, Wegiel J, Popovitch ER. Age-associated development of diffuse and thioflavin-s-positive plaques in development of diffuse and thioflavin-s-positive plaq
Down syndrome. Dev Brain Dysfunct 1994;7:330-9.

39 Wang D, Munoz DG. Qualitative and quantitative differences in senile plaque dystrophic neuritis of Alzheimer's disease and normal aged brain. I Neuropathol Exp Neurol 1995;54:548-56.

40 Wisniewski HM, Wegiel J, Kotula L. Some neuropathological aspects of Alzheimer's disease and its relevance to other disciplines. Neuropathol Appl Neurobiol 1996;22:3-11.

41 Hansen LA, Masliah E, Galasko D, et al. Plaque-only Alzheimer's disease is usually the Lewy body variant and vice versa. F Neuropathol Exp Neurol 1993;52:648-54.

42 Price RW, Brew B, Sidtis J, et al. The brain in AIDS: central nervous system HIV-I infection and AIDS dementia complex. Science 1988;239:586-92.

43 Peavy G, Jacobs D, Salmon DR, et al. Verbal memory performance of patients with human immune deficiency viruses infection: evidence of subcortical dysfunction. $\mathcal{F}$ Clin Exp Neuropsychol 1994;16:508-23.

44 Stanley LC, Mrak RE, Woody RC, et al. Glial cytokines as neuropathogenic factors in HIV infection: pathogenic similarities to Alzheimer's disease. $f$ Neuropathol Exp Neurol 1994;53:231-8.

45 Mucke L, Abraham CR, Ruppe MD, et al. Protection against HIV-1gp120-induced brain damage by neuronal expression of human amyloid precursor protein. $\mathcal{F}$ Exp Med 1995;181:1551-6.

46 Esiri MM. Typical and atypical viruses in the aetiology of senile dementia of the Alzheimer type. In: Ulrich J, ed. Histology and histopathology of the ageing brain. Interdisciplinary topics in gerontology. Basel: Karger, 1988;25:119-39.

47 Itzhaki R, Lin WR, Shang D, et al. Herpes simplex virus type 1 in brain and risk of Alzheimer's disease. Lancet 1997;349: 241-4. 